\title{
Sonlu Bir Yarıgrubun Geniş Rankı İçin Alternatif Bir Metot
}

\author{
Osman KELEKCI் ${ }^{1 *}$ \\ ${ }^{1}$ Niğde Ömer Halisdemir Üniversitesi, Fen Edebiyat Fakültesi, Matematik Bölümü, 51240, Niğde \\ okelekci@ohu.edu.tr
}

Geliş / Received: 16/01/2020, Kabul / Accepted: 31/08/2020

\section{Öz}

Bu çalışmada, en küçük asal alt küme tanımı kullanarak sonlu bir yarıgrubun geniş rankını bulmak için alternatif bir yaklaşım ele alınmıştır. Bu bağlamda, $T_{n}$ dönüşümler yarıgrubunun geniş rankı için daha sade bir ispat verilmiştir. Ayrıca, dikdörtgensel bir bantın ve devirli bir grubun geniş rankları bu yöntemle tekrar hesaplanmiştır.

Anahtar Kelimeler: Geniş rank, Dönüşüm yarıgrubu, Dikdörtgensel bant, Devirli grup.

\section{An alternative method for the large rank of a finite semigroup}

\begin{abstract}
In this work, an alternative approach to find the large rank of a finite semigroup using the smallest prime subset is discussed. In this sense, a simpler proof is given for the large rank of the transformation semigroup $T_{n}$. Additionally, large ranks of a rectangular band and a cyclic group are recalculated by this method.
\end{abstract}

Keywords: Large rank, Transformation semigroup, Rectangular band, Cyclic group.

\section{Giriş}

Yirminci yüzyılın ikinci yarısından itibaren cebirin bir alt dalı olarak başlı başına bir araştırma alanı olmaya başlayan yarıgrup teorisinde en önemli problemlerden birisi yarıgrupların sınıflandırılmasıdır.

Lineer cebirdeki boyut kavramı ile benzerlik gösteren rank kavramı, cebirsel yapıların sinıflandırılmasında önemli bir rol oynar. Grup teorisinde rank tek türlü tanımlanırken,

*Corresponding Author: okelekci@ ohu.edu.tr yarıgrup teorisine genişletildiğinde farklı değerler veren rank tanımları yapılabilir.

Bu noktada, Howie ve Riberio (1999),(2000) iki çalışmasında toplamda beş çeşit rank tanımlamışlardır. Bu ranklar farklı yarıgrup yapıları için hesaplanmıştır. (Kelekci 2011) ve (Minisker 2009).

$\mathrm{Bu}$ çalışmada ise geniş rank kavramına odaklanılmış, asal alt küme tanımıyla $T_{n}$ dönüşümler yarırubunun geniş rank1 için daha kısa bir ispat verilmiştir. Ayrıca dikdörtgensel bir bantın ve devirli bir grubun 


\section{Sonlu bir yarıgrubun geniş rankı için alternatif bir metot}

bilinen geniş rankları yine asal alt küme ile yeniden hesaplanmıştır.

\section{Materyal ve Metot}

$Y$ sonlu bir yarigrup olsun. $A \subseteq Y$ olmak üzere $\forall a \in A \subseteq Y$ için $a \notin\langle A-\{a\}\rangle$ ise $A$ ya $Y$ nin bă̆ımsız bir alt kümesi denir.

$$
\begin{aligned}
& \text { - } r_{1}(Y)=\max \left\{\begin{array}{c}
|A|: \forall A \subseteq Y, \\
A \text { bă } \iota m s l z
\end{array}\right\} \\
& \text { - } \quad r_{2}(Y)=\min \left\{\begin{array}{c}
|A|: \exists A \subseteq Y, \\
\langle A\rangle=Y
\end{array}\right\} \\
& \text { - } r_{3}(Y)=\max \left\{\begin{array}{c}
|A|: \exists A \subseteq Y, \\
A \text { bă } \iota m s ı z \\
v e\langle A\rangle=Y
\end{array}\right\} \\
& \text { - } r_{4}(Y)=\max \left\{\begin{array}{l}
|A|: \exists A \subseteq Y, \\
A \text { bă } \mathrm{g} \iota m s l z
\end{array}\right\} \\
& \text { - } r_{5}(Y)=\min \left\{\begin{array}{c}
|A|: \forall A \subseteq Y, \\
\langle A\rangle=Y
\end{array}\right\}
\end{aligned}
$$

şeklinde olup sırasıyla küçük, alt, orta, üst ve geniş rank olarak isimlendirilmiştir. Uzun süredir çalışılagelen minimum doğuray kümesinin kardinalitesi yani normal rank burada alt ranka tekabül etmektedir.

Kolayca gösterilebilir ki, $r_{1}(Y) \leq r_{2}(Y) \leq$ $r_{3}(Y) \leq r_{4}(Y) \leq r_{5}(Y)$ dir.

Çalışma boyunca açıklanmayan terimler için Howie (1995) e bakını.

\section{Bulgular}

$V, \quad Y$ yarıgrubunun boştan farklı bir alt kümesi olsun. $V$ kümesinin asal olması için gerek ve yeter şart $\forall x, y \in Y$ için $x y \in V$ ise ya $x \in V$ ya da $y \in V$ dir. Bu asal alt küme tanımından hareketle Kumar ve Krishna (2014) nın önermesini verelim.

Önerme 3.1. $U$, sonlu bir $Y$ yarıgrubunun uygun bir alt kümesi olsun. $U$ nun $Y$ yarıgrubunun en küçük asal alt kümesi olması için $\Leftrightarrow Y-U$ kümesinin $Y$ yarıgrubunun en geniş öz alt yarıgrubu olmasidir.

İspat: $Y-U$ kümesinin $Y$ nin bir alt yarıgrubu olmaması için $x, y \in Y-U$ iken $x y \notin Y-U$ olmas1 gerekir. $x y \notin Y-U$ olması ise $x y \in U$ olacak şekilde $x, y \notin U$ elemanlarının var olması demektir. $\mathrm{Bu}$ ise yalnızca $U$ nun asal bir alt küme olmaması ile mümkündür. $\mathrm{O}$ halde $U$ asal bir alt kümedir. Şimdi $U$ nun en küçük olduğunu gösterelim. $Y$ nin $A$ ve $B$ gibi iki alt kümesini alalım. $|A|+|Y-A|=|B|+|Y-B|$ olduğundan $|A|<|B|$ olması ancak ve ancak $|Y-B|<|Y-A|$ ile mümkündür. $\mathrm{O}$ halde $U$ en küçüktür.

$\mathrm{Bu}$ önerme ile Howie (2000) deki geniş rank için verilen teorem, aşağıdaki sonuçla da ifade edilebilir.

Sonuç 3.2. $U, Y$ yarıgrubunun en küçük asal alt kümesi olsun. $\mathrm{O}$ zaman $r_{5}(Y)=$ $|Y-U|+1$ dir.

Teorem 3.3. $T_{n}, X_{n}=\{1,2, \ldots, n\}$ kümesi üzerinde tanımlanabilecek tüm dönüşümler yarıgrubu olsun. $\mathrm{O}$ zaman $r_{5}\left(T_{n}\right)=n^{n}-$ $\left|A_{n}\right|+1$ dir.

İspat: $T_{n}$ dönüşümler yarıgrubunun tüm elemanları Green denklik bağıntıları aracılığıyla $\quad D$-siniflarında (eggbox) gösterilebilir. $\mathrm{Bu} D$-sınıfları dönüşümlerin imajlarındaki eleman sayılarına bakılarak isimlendirilirler. Yani $T_{n}$ nin $n$ tane $D$-sınıfi vardir. $D_{1}, D_{2}, \ldots, D_{n}$ siniflarından $D_{n}=S_{n}$ dir. $T_{n}$ nin her doğurayı $S_{n}$ nin (simetrik 


\section{Sonlu bir yarıgrubun geniş rankı için alternatif bir metot}

grup) doğurayını içermek zorunda olduğundan ve $i \leq n-1$ olmak üzere $D_{n^{-}}$ sınıfları için $\operatorname{im}(\alpha \beta) \subset \operatorname{im}(\alpha)$ olduğundan yani dönüşümleri çarparak imaj1 arttıramayacağımız için en küçük asal kümeyi bulmak için $S_{n}$ e bakmak yeterlidir. En küçük asal alt kümeyi $S_{n}$ nin içinde aramalı ve bu küme $S_{n}$ yi doğurmayan elemanlardan oluşup maksimum eleman sayılı küme olmalıdır. $\mathrm{Bu}$ küme ise tam olarak $A_{n}$ Alterne gruba eşittir.

Örnek: $T_{3}$ yarıgrubunu göz önüne alalım. $U=\left\{\left(\begin{array}{lll}1 & 2 & 3 \\ 1 & 2 & 3\end{array}\right),\left(\begin{array}{lll}1 & 2 & 3 \\ 2 & 3 & 1\end{array}\right),\left(\begin{array}{lll}1 & 2 & 3 \\ 3 & 1 & 2\end{array}\right)\right\}$ kümesi en küçük asal alt kümedir. Dolayısıyla $r_{5}\left(T_{3}\right)=3^{3}-\frac{3 !}{2}+1=25$ dir. Yani 25 elemanlı her alt küme $T_{3}$ ü doğurur.

Teorem 3.4. $m, n \geq 2$ ve $m>n$ olmak üzere $R_{m n}$ dikdörtgensel bir bant olsun. $\mathrm{O}$ zaman $r_{5}\left(R_{m n}\right)=m n-n+1$ dir.

İspat: Dikdörtgensel bir bant $i, j \in$ $\{1,2, \ldots, m\}$ ve $\alpha, \beta \in\{1,2, \ldots, n\}$ olmak üzere, $(i, \alpha)(j, \beta)=(i, \beta)$ işlemi ile bir yarıgruptur ve $R_{m n}=\{1,2, \ldots, m\} \times$ $\{1,2, \ldots, n\}$ şeklinde gösterilir. Ayrıca $L$ bir sol sifir yarıgrup ve $R$ bir sağ sifir yarıgrup olmak üzere $R_{m n} \cong L \times R$ dir. Yani $L=$ $\{1,2, \ldots, m\}$ ve $R=\{1,2, \ldots, n\}$ alabiliriz. Sol ve sağ sıfır yarıgrubun bütün elemanları indirgenemez olduğu için en küçük asal alt küme $|n|$ elemanlı olmalıdır ve bu küme keyfi bir $\quad i \in L \quad$ için $U=\{(i, 1),(i, 2), \ldots,(i, n)\} \quad$ şeklindedir. Çünkü seçilen bu $i \in L$ elemanını diğer elemanların mümkün çarpmalarından elde edemeyiz. Dolayısıyla Sonuç 3.2. den ispat biter.

Teorem 3.5. $n \geq 2$ olmak üzere $C_{n}, n$ elemanlı devirli bir grup olsun. O zaman $p, n$ yi bölen en küçük asal olmak üzere
$r_{5}\left(C_{n}\right)=\left\{\begin{array}{c}2, \text { n asal ise } \\ \left|\left\langle a^{p}\right\rangle\right|+1, n \text { asal değil ise }\end{array}\right.$ dir.

İspat: Devirli bir grupta indirgenemez eleman yoktur. Bu yüzden $n$ nin asal olduğu durumda, birim eleman hariç bütün elemanlar en küçük asal alt kümenin elemanı olmak zorundadır. Yani $U, C_{n}$ nin en küçük asal alt kümesi ise $|U|=n-1$ dir. Birim elemanın yanına hangi elemanı seçersek seçelim $C_{n}$ i doğurur. Buradan $r_{5}\left(C_{n}\right)=2$ dir. $n$ nin asal olmadiğ 1 durumda ise, $\left\langle a^{p}\right\rangle=\left\{a^{p}, a^{2 p}, \ldots, a^{n}=a^{0}\right\}, \frac{n}{p}$ elemanlı bir alt gruptur. Dolayısıyla en küçük asal alt küme, $\left\langle a^{p}\right\rangle$ alt grubunun elemanları hariç diğer bütün elemanlardır. O zaman en küçük asal alt küme $\left|n-\left\langle a^{p}\right\rangle\right|$ elemanlı olmalıdır. Sonuç 3.2. den sonuç elde edilir.

\section{Sonuç ve Tartışma}

En küçük asal alt küme kavramı yardımıyla $r_{5}\left(T_{n}\right)$ yeniden ispatlanmıştır. Ayrıca dikdörtgensel bantın ve devirli grubun geniş rankları yine asal alt kümeler vasitasıyla bulunmuştur.

Sadece geniş rank değil diğer bütün ranklar, çalışılmayan diğer cebirsel yapılar için çalışılabilir.

\section{Kaynaklar}

Howie, J.M. (1995). "Fundamentals of Semigroup Theory", Oxford University Press, New York.

Howie, J.M. and Riberio, M. I. M. 1999. "Rank properties in finite semigroups", Comm. in Algebra, 27(11), 5333-5347. 
Howie, J.M. and Riberio, M. I. M. 2000. "Rank properties in finite semigroups II: the small rank and the large rank", Southeast Asian Bull. Math., 24(2), 231-237.

Kelekci, O. 2011. "Upper Rank of Full Transformation Semigroups on a Finite Set", International Journal of Algebra, 5(31), 1527-1532.

Kumar, J. and Krishna, K.V. 2014. "The large rank of a finite semigroup using prime subsets", Semigroup Forum, 89(2), 403-408.

Minisker, M. 2009. "Rank properties of certain semigroups", Semigroup Forum, 78(1), 99-105. 